\title{
Banishing Financial Untouchability of the Poor through PMJDY - A Tryst with New Destiny
}

\author{
Ipseeta Satpathy \\ Professor, School of Management, KIIT University, Odisha, India \\ Email-ipseeta@ksom.ac.in \\ B.Chandra Mohan Patnaik \\ Associate Professor, School of Management, KIIT University, Odisha, India \\ Email-bcmpatnaik@gmail.com \\ Pradeep Kumar Das \\ Research Scholar, School of Management, KIIT University, Odisha, India \\ Email-pkdas21738@gmail.com
}

\section{Doi:10.5901/mjss.2015.v6n2p184}

\begin{abstract}
Unrestrained access to financial products and services without any discrimination for the people at the bottom of social pyramid is an elusive goal even after 68 years independence. The social malaise of exclusion has plagued Indian Sub-continent particularly the marginalised population who have been deprived of the benefits of economic growth since independence. A large chunk of unbanked low income people are still reeling under the vicious grip of informal money lenders paying exorbitant interest rates which develops pauperism in wide scale. Govt. and RBI have endeavoured with a slew of measures towards attaining faster and inclusive growth since announcement of Annual Policy of RBI in 2005-06 and beginning of Eleventh Five Year Plan As an economic imperative, the financial inclusion plans of 2010-13 and 2013-16 were pursued with much vigor which failed to make a real dent in addressing the unmet demand of the huge excluded population. The non -availability of basic banking services were primarily attributed to the paradigm shift in policy stance of RBI in moving towards a market-driven policy frame work which focused on innovative product, place( geographical proximity) , price(affordable price of services), protection(client safety) and profitability of the business model implemented by Banks for increasing outreach and access to financial services of the excluded people. The new regime have endeavoured to plug the bottlenecks and repackaged the Financial Inclusion plan with the goal of universal access to Basic Services for all unbanked households by March 2016. With this laudable PMJDY launched by Hon'ble Prime Minister Narendra Modi on August 28, 2014with unequivocal focus on removing the bane of financial untouchability,. Growth with equity is the key challenge and economic well-being and prosperity for all is the central theme of the developmental policy
\end{abstract}

Keywords: Prime Ministers Jan Dhan Yojana , ICT(Information and communication technology), financial untouchability.

\section{Introduction}

Indian has undertaken a journey of 68 years in post-independence era and twenty-three years after banking and financial sector reforms were ushered, the financial sector still plagued from ills of providing universal access to financial services like savings deposits, credit facility, fund remittance, insurance (life /non-life) to mitigate risk and pension services etc. which holds the key to economic development and improving the living standards / quality of life. Formal banking services have been categorised as public goods and universal access by every household is an essential part of public policy. The objective is to enable the poor unbanked population to come out of vicious cycle of moneylenders, equip them with the capability to manage financial crises by bridging the information asymmetry of the mainstream banking with greater awareness of financial products and services. The changed stance of market-led policy of financial inclusion was vociferously promoted which financial inclusion like with product, place, price, protection and profit ( speech delivered by Governor Dr Raghuram .Rajani on 20th Lalit Doshi Memorial Lecture on 11 August 2014 in Mumbai) which is distinctly different from the traditional egalitarian approach and strategies of financial inclusion pursued so far.

With the onset of communication and technological revolution the Indian banking industry has undergone rapid 
transformation with complexity of product and services which has far reaching implications on the financial viability, profitability and competitiveness of the banks. But the major concern for the Indian Banking sector has been its failure to bring the underprivileged/underserved population into the ambit of mainstream economy.

The major handicaps which are encountered by economically backward people low skills, low asset base and other maladies like illiteracy, lack of physical infrastructure and geographically difficult hinterlands and price barriers like high cost of transactions and minimum balance criteria in savings bank as also inconsistent and low income and other price barriers and also non price barriers which deters them to remain aloof from mainstream banking,

Building inclusive financial system is the sine qua non of development policy which entails all economically active and "bankable" individuals gets access to savings, credit; insurance and payment services on continuous basis without any bias and discrimination at affordable costs. Low and inconsistent income is often happens to be the primary factor that contributes to financial exclusion being affected by twin factors of supply and demand sides of the inclusion process

The poor are less motivated to fully participate with the formal sector due to lack of availability of suitable financial products, as also inability to save due to inconsistent cash flow In simple terms opening of bank accounts may be construed as the sole objective of financial inclusion but in essence the concept is much broader of not only providing access but to empower the people for its usage for improving the overall standard of living.

The deleterious effect of exclusion results in skewed distribution of income and income inequality become more conspicuous which inhibits growth and development. The inclusive growth is facilitated by access to savings and credit facilities of the mainstream banking that push the domestic savings and capital formation which has been propounded by ILO Declaration of Philadelphia in 1944 Hence, Hence inclusive banking is sine qua non to sustainable development..

The stigma of exclusion being the cause which plagues the sustainable development of developing countries was also echoed by former United Nations Secretary-General Kofi Annan, on 29 December 2003, recognising the need to build an inclusive financial system . He was supportive of providing opportunity to the vulnerable population for effective participation in the financial system and shaping the process of development of the economy in emerging countries.

It is increasingly recognised through empirical studies and comparison with other developed countries that the key dimensions of financial development lies with unrestrained financial access, financial depth through wide financial network and empowerment with financial literacy, efficiency and quality of products and services and affordability with cost effective technology solutions provide an enabling environment for inclusive growth, accelerates develop economic development, reduces inequality, and provides bigger benefits to those at the lower end of the income distribution. India still cherishes to achieve the goal of universal access to financial system.

Indian economy recognised as the second fastest growing economy in the world but the story of exclusion of the unbanked people dwelling in rural areas depicts a gloomy picture. Out of total 24.67 crore households in the country as per Census 2011,, only 58.70 percent households (14.48 Cr) have access to formal banking services . The situation is far worse as 9.14 crore rural households (54.46\%of total) have the opportunity to access the formal financial system, even after 20 years of Banking Sector reforms. The World Bank Findex study of 2012 further elucidates the grim situation as the developing countries with average access of $41 \%$ compared to $35 \%$ of Indian population particularly in rural areas.

So, it leaves a huge chunk of rural and semi-urban Indians in the hands of unorganised, unscrupulous moneylenders. The usury of moneylenders and its impact on poor farmers in swathes of rural India has been evident despite the progressive initiatives of Govt. and RBI since RBI Annual Policy pronouncement in 2005-06 and specific thrust in the Eleventh Five Year Plan towards a faster and inclusive growth and Khan Committee Recommendations in 2004 and Committee on Financial Inclusion by Dr.C Rangarajan all advocating for complete financial inclusion based on egalitarian approach of broad based growth.

\section{Consequences of Exclusion and the Significance of Inclusive Agenda}

The exclusion of the vast population from the mainstream economy has adverse and deleterious effects on the financial system and society at large. The inability to access financial services encourages financially excluded people to deal mostly in cash which leads to problems of safe-keeping and fails to develop any transaction history and credit records for the people to be eligible for higher credit by banks. Moreover it provides a platform to save and promotes investment and capital formation in the economy and relieves from the shadow of financial duress which is a regular feature.

The vulnerability of the unbanked population is reduced to a great extent by access to credit products from formal channels and keeps them away from informal channels like money lenders. This promotes entrepreneurial spirit towards higher output and productivity and improves their livelihoods for a decent living. The contribution of MFIs and SHG-Bank Linkage promoted by RBI is a classic example for sustainable livelihood of the underprivileged women availing formal avenues of credit. 
The pressing needs of payment and remittance facilities which the marginalised people being met through informal sources leads to money transfers to be costly affair and also cumbersome. The lack of awareness of insurance products deprives of the opportunities of mitigating risk of the life and non -life assets and smooth management of personal wealth. Apart from this, the leakages and gaps in administering the public subsidies are also minimised through efficient and affordable banking system

\section{Objective of the Study}

In spite of the core development philosophy of inclusive growth pursued vigorously by our policy makers and planners since of last couple of years with the objectivity for broad basing the growth and banishing the social malaise like social and financial exclusion even after the passage of 68 years of independence, the present study attempts to make a deeper understanding of the subject relating to multifarious issues and challenges faced by all the stakeholders in the process of building an inclusive financial system as a precursor to inclusive growth. The major objective of the study is outlined as under;

1. To critically evaluate the underlying causes of exclusion leading to financial untouchability and tackling the challenge through complete financial inclusion as the national priority,

2. To evaluate the progress made in achieving the twin objectives of demand-supply gaps of unbanked population and corrective measures taken.

3. To discuss the conceptual perspectives of PMJDY as the new weapon of the government and its effectiveness in achieving Universal Financial Inclusion.

\section{Methodology of Study}

Secondary research has been undertaken to review the impact and effectiveness of FI initiatives of govt. and RBI and Indian Banking system in achieving the objective of inclusive financial system from the data collected through secondary sources like published articles, journals, reports and websites. The concept of Jan Dhan Yojana being a recent one which was launched on August 28, 2014 by the Prime Minister and the modalities /institutional mechanism of the flagship programme is still evolving, at this juncture it is felt that any effort to undertake any empirical study based on primary sources may not elicit any pragmatic/realistic assessment of the programme.

\section{Limitations}

The study is based on the secondary data sources which covers a limited period say three years' time horizon which is not sufficient to draw a conclusive evidence of the impact of the $\mathrm{FI}$ initiative. Moreover, the traditional $\mathrm{FI}$ initiative undertaken by previous govt. and the PMJDY launched by present regime still overlaps in the approach and the two are yet to draw a clear line and synergy in strategy and implementation in achieving the universal financial inclusion of the target population

\section{Literature Review}

A number of studies have been undertaken to study the various dimensions of Financial Inclusion, the factors contributing to exclusion of low income and marginalised people, correlation between financial inclusion and economic development, access to financial services and its impact on the financial empowerment of low income people and improvement on the quality of life in emerging economies like India. We append some of the studies relevant to the subject

Leeladhar, V. (RBI Bulletin Jan 2006), Financial Inclusion is delivery of Banking services to the vast sections of underprivileged people at an affordable cost. As banking services is treated as public utility services, it is essential that availability of banking and payment services be made available to all citizens of the country without any discrimination.

Thorat Usha (2008), Dy. Governor, Reserve Bank of India has emphasized the need for Financial Inclusion as the key to sustainable growth during her address on'Vision-2020- Indian Financial Services Sector' hosted by NDTV. She highlighted the emerging challenges in the coming days that requires building synergy between Micro Finance Institutions and Self Help Groups and Banks for implementing ICT based seamlessly also advocated that Financial Inclusion requires skilled manpower to manage IT platform successfully.

Teki.S \& Mishra R.S : Role of Microfinance in Financial Inclusion P 87, 2013 has observed that Microfinance through its innovative dealing of "helping people to help themselves" has successfully explored $d$ the myth that poor 
people are not worthy of being banked upon. The 2006 Nobel Peace prize to Prof Mohammed Younus for Grameen Bank shows the success and relevance of the concept of Microfinance. The Financial Inclusion is a step further by not just treating the poor as different but by considering them as credit worthy citizens and bankable consumer.

Puhazhendi, Venugopalan (2012), "Financial Inclusion-Forward step for Microfinance Sector", Vol 83, June , P.30 in Indian Institute of Banking 7 finance has emphasized the need to increase the share of institutional credit, and decrease the dependence of small and marginal farmers on non-institutional sources, access to credit between developed regions and less developed regions has widened. Hence to attain comprehensive Financial inclusion the share of rural credit from institutional sources needs to be given wider coverage and demand driven new financial products with cost effective delivery mechanism supported by modern technology be developed. Micro finance being a sector that serves very large number of small clients distributed over wide and inaccessible geographical may be cost intensive. To meet the requirement roles of the players like SHG and MFIs equipped with new technological platforms with cost effective and newer financial products designed to suit the targeted customers will smoothen the effort in delivering microfinance to a higher level.

Khan H.R.: Financial Inclusion and Financial Stability: Are they two sides of the same coin.: Address by Deputy Governor of Reserve Bank of India at BANCON 2011 organized by Indian Bankers Association and Indian Overseas Bank, Chennai, November 4, 2011 has stated that financial inclusion is intimately related to financial stability which requires providing universal access to basic financial services to a wider segment of population/society which in turn will financial stability and sustainable economic growth .Providing access to basic financial services has become a compulsive agenda and integral part of development philosophy actively pursued by planners and administration to make inclusive growth a reality..

\section{Initiatives to Remove the Exclusion and Strategy Adopted}

Broad basing the financial inclusion with enhancing the outreach and deepening the penetration through access to formal banking products and services have been the pursued goal during last several decades, but the outcome is not encouraging The various initiatives include nationalization of banks in 1969 and 1980, directed credit through prescribed priority sector lending requirements, adopting pluralistic approach to rural finance to meet the unmet demand for financial services which included making Lead Bank Scheme operational in all the districts of the country, launching Regional Rural Banks (RRBs) as a major player, strengthening Primary Agri Credit Cooperative Societies and cooperative structure, Service Area Approach for directed credit, Self-Help Group-Bank - Linkage(SBPL) Programme- all innovative programmes operationalized with the aim of extending banking services to the unbanked masses. Post 1991, steps for strengthening financial institutions with market orientation for better efficiency and profitability were aimed as part of financial sector reforms for up scaling the inclusive growth. But all such endeavours have left a huge trail of the underserved/unserved population to large extent and the financial exclusion has remained a big challenge facing the nation.

\subsection{The bottlenecks of the efforts towards increasing outreach}

Target orientation: The social banking was heavily biased for achieving quantitative targets .Banks never integrated social banking strategies with own business strategy for up scaling the efforts. The social and mass banking initiative of Banks was never perceived as a business opportunity and profitable proposition. Poor people were not considered bankable. Formal Banking institutions have not taken interest in exploring the business opportunities in rural India and experiment with viable business models to realize the true potential

ILL effects of market driven policies :The financial sector reform and consolidation of banks was the major shift in Indian Banking scene with market driven policies could not synchronise with financial inclusion measures in an effective manner and mass banking initiatives were on back burner during 1991 up to 2005.

Entrusting Responsibility to Public sector Banks :The social obligation of Banking system rests on the public sector banks predominantly while social commitments is not a priority agenda for the private sector banks and foreign banks.

Lack of innovative technology: Reaching the people at hinterlands and difficult terrains without an appropriate and cost effective technology nor having physical access to branch, was a difficult proposition. 


\subsection{The New Dimension of inclusive agenda}

Apart from non-availability of viable /sustainable business and delivery model, non-availability of cost effective technology as an enabler etc were some of the major barriers for poor show of financial inclusion in earlier days. At present the said gaps have been overcome by developing affordable and effective solutions for extending the outreach and bring the excluded unbanked population residing in six lakh plus villages in the country. The lessons learnt from the implementation of earlier Financial Inclusion strategy since 2005-06 provided invaluable insights into the realities. This culminated in redesigning the new framework of accelerated drive to Financial Inclusion.

\subsection{The Approach of RBI for effecting Financial Inclusion}

The progress in financial inclusion initiative of earlier period was far from satisfactory which forced the regulators and policy makers to have a rethink on the approach. It began with redefining the perspectives on financial inclusion and the major contours of the new approach.

Reserve Bank of India has outlined the main focus of Financial Inclusion into two major dimensions

A) Providing universal access to suitable financial products and services particularly the weaker sections and low income groups

B) Affordability of financial products and services in a fair and transparent manner by mainstream institutional players

Thus, financial inclusion has two fold objectives:

1. To connect the low income people with the formal banking system through financial counselling for empowering them for better financial decision making and personal wealth management.

2. Providing door step banking services to the unbanked population to cater to the need of basic banking services like savings, credit, insurance, pension and remittance etc.

\subsection{The Approach of Financial Inclusion redefined}

With the shift in focus since 2005-06 towards accelerated and inclusive growth strategies for broad basing the process, the issues of demand and supply of financial services were planned to be addressed in a structured manner.

The demand side factors encompassed the initiatives to develop financial capability through financial literacy of the low income people and overcoming the psychological and cultural barriers. The supply side gaps such as simplification of documentation procedure for opening accounts, minimising physical barriers through enhanced financial network of branches/door step banking through BC/BF and providing appropriate financial products to suit the needs of rural customers were aimed at creating a congenial environment for the banks.

To meet the objective requirement Reserve Bank of India has embarked on multipronged strategies which covered designing new products and support services as well as relaxation of regulatory controls in order to create a congenial environment for broader access to formal banking services detailed as under:.

Formal Banking institutions having requisite infrastructure, financial prowess, innovative technology with flexibility for customisation to cater to needs of rural poor were assigned the responsibility to lead the flagship programme

Reserve Bank has permitted banks to utilise the services of Business Correspondent/ Business Facilitator Model as intermediaries in providing financial and banking services at doorstep of the unbanked population.

Simplified branch authorisation was introduced by RBI to facilitate expansion of branch network with removal of the restriction for opening branches in centres having population below 1 lakh and a stipulation to open at least 25 per cent of new bank branches in unbanked rural centres.

In order to leverage innovation of technology ICT Based Accounts with, the use of smart cards, and bio-metric authentication facilitates were advocated towards digitization of Financial Inclusion process. The balance combination of Business correspondents and geographical distribution of bran network the key to enhance the access points to Banking outreach.

Opening of Basic Saving Bank Deposit Accounts with zero balance coupled with RuPay Debit card was made a fundamental right for every eligible Indian citizen. To support the easy compliance, E-KYC leveraging AADHAR platform was permitted for availing the Direct Benefit Transfer as an incentive.

For easy access to credit facility from formal banking system, KCC for households with farming and GCC for households with non-farm operations have been simplified to develop the spirit of entrepreneurship for livelihood.

Relaxed KYC norms for opening small accounts by self-certification 
Interest rate on advances has been deregulated to give mileage to Financial Inclusion plan of Banks.

\subsection{Role of Financial Literacy}

The disparity in literacy level across regions, skewed socio-economic development, multiple regional languages, low skills, lack of bargaining power and information asymmetry have compounded the barriers to access and usage of financial services by the underprivileged and downtrodden masses for which national project initiated to

\subsection{Progress made under Financial Inclusion}

With the initiatives taken by govt. and RBI and implemented by Indian Banks, the performance of first phase of implementation under Financial Inclusion Plan as on 31.03.2014 (Source :Annual Report of Reserve Bank of India 201314)are appended:

I. With the opening of, 1,15,350 banking outlets during 2013-14, the total banking outlets in the country has increased to 384000 which is significant step in increasing the outreach..

II. During the year 2013-14, total 5300 branches in rural centres were opened of which 4600 are located in unbanked centres.

III. With emphasis to remove exclusion at urban centres, BC outlets increased to 60,730 as at the end of March 2014.

IV. During the year new Basic Savings Bank Deposit Accounts (BSBDAs) of 60 million were opened which increased the figure to 243 million.

V. The coverage of small farm sector credit has increased to 40 million while the non-farm sector credit has improved to 7.4 million at the end of the March 2014.

VI. The no of transactions at BC out lets through BC-ICT accounts amounted to 328 million which is a sizeable growth over 2012-13 amounting 250 million transactions

\section{PMJDY Launched with Holistic Approach}

The implementation of the Financial inclusion plan during the period 2010 to 2013 with the intervention of RBI failed to make any giant leap and the unbanked population deprived of banking access remained almost half of the Indian population (42\%) as per 2011 Census and the goal of complete financial inclusion still remained an elusive goal. To overcome the constraints and paving the way for a tangible impact towards universalisation of financial access,. PMJDY is a flagship programme announced by Prime Minister on 15 August 2014 during his maiden independent day speech to the nation which was formally launched nationwide on 28 August 2014.The sole objective was to provide 'universal access to formal banking for each household with access to at least a bank account by January 2016.

The scheme has been meticulously planned and robustly designed addressing all the possible deficiencies learnt from the implementation of Financial Inclusion plan during the first phase 2010-2013.The approach adopted so far was broadly egalitarian in nature intended to ensure economic development for all equitably i.e Sabka Vikash Sabke Sath. It emphasises on the need to broad base the development with providing opportunities to the underprivileged and downtrodden to participate actively through complete inclusion with the financial mainstream. The implementation of the scheme has been planned to be in mission mode with strong monitoring mechanism at five levels -three at the centre and two at state levels headed by Finance Minister.

The Pradhan Mantri Jan Dhan Yojana(PMJDY) forms the essence of development philosophy for the economic upliftment of the poor and vulnerable. Every household to be provided access to banking, credit facilities and other financial services like remittance services and insurance products for mitigating risk, flow of direct benefit transfers under several welfare programmes of the poorer sections of the society. The financial access through formal banking system is expected to enable households benefit from a range of financial products and reduce the financial vulnerability caused by unforeseen situations. This would also enable them to come out of the grip of usurious moneylenders. The distinct advantage of the scheme enables every account holder with an inbuilt advantage of a RuPay debit card with accident cover of Rs 100000/- and an overdraft facility in due course to one member of the family preferably lady member. It also empowers the unbanked people with financial education for stimulating demand as well as usage of the banking services in effective manner for economic well-being.

The path breaking initiative has been planned to be executed in two phases: 


\subsection{Phase-I (Period: 15th August 2014 to 14th August 2015)}

The access to formal banking facilities for all households across the country has been proposed to be universalise through a bank branch or a fixed point Business Correspondent (BC) within a reasonable distance To achieve the objective, mapping of each district into Sub Service Area (SSA) covering 1000-1500 households has been started in a way that every household can get access to banking services within a the reasonable distance say $5 \mathrm{~km}$ by 14 August, 2015.

The agenda proposes to cover every households with access to at least one Basic Banking Accounts with RuPay Debit card .This will have inbuilt accident insurance cover of Rs.1 lakh. Further an overdraft facility up to Rs.5000 will also be permitted to Aadhaar enabled accounts after satisfactory operation in the account for 6 months preferably to one ladies member of the household.

Financial literacy programme of the underprivileged is integrated to be undertaken bank branches on regular basis to build awareness on financial products and services up to village level to bridge the gap of information asymmetry in banking system for the common man.

For keeping the zero balance accounts operational and active, the scheme envisages Direct Benefit Transfer of subsidies under various Government Schemes through bank accounts of the beneficiaries with seeding of Aadhar numbers.

The Kisan Credit Card (KCC) in the form of RuPay Kisan Card is also proposed to be issued in large numbers under the plan.

\subsection{Phase-II (Period: 15th August, 2015 to 14th August, 2018):}

Envisages providing micro - insurance (life cover) of Rs 30000/- to the willing and eligible persons by 14 August, 2018, and then on an ongoing basis.

Unorganised sector Pension schemes like Swavalamban through the Business Correspondents and then on ongoing basis.

\subsection{The unique features of PMJDY}

The programme is unique in its approach and have distinct advantage over other similar initiatives undertaken so far to tackle the huge challenge of exclusion which are enumerated as under:

There is shift in approach to Households being targeted instead of villages with population density targeted earlier.

Both rural and urban population are the targeted beneficiaries as against only rural population targeted earlier.

The scheme will unfold digital financial inclusion with use of USSD mobile platform and other innovative technological initiatives with special emphasis on monitoring by a Mission headed by the Finance Minister.

The financial literacy is the major plank to be undertaken in an intensive campaign mode to develop awareness of financial products, inculcate banking habits and increase usage of banking system and build credit history of the masses for higher credit entitlements in a graduated manner.

The cumbersome Know your customer guidelines have been simplified which restricted opening of basic savings bank accounts.

Minimum remuneration of banking correspondents has been prescribed based on viability to minimise inoperative accounts. Banking correspondents are vital links for providing doorstep banking service under the scheme

To minimise the number of inoperative accounts opened under PMJDY, Direct Benefit Transfer (DBT) will be undertaken through Aadhar platform which provides an incentive to open accounts under the scheme.

\subsection{Strategy for effective Implementation of PMJDY}

Keeping in view the colossal task to overcome the problem of exclusion, there is need for broad collaboration of all stake holders which requires great synergy and convergence inter -department functioning, optimal utilisation of rural infrastructure and giving impetus to public-private partnership .Geographical expansion of bank branches network coupled with opening of outlets of Banking correspondents technological products like Rupay Card and mobile banking, use of micro ATMs and UIDAls scheme for E-KYC are the major hall marks which would give a cutting edge to the mission. Gradual convergence with the National Rural Livelihood Mission (NRLM) in rural areas and National Urban Livelihood Mission (NULM) in urban areas will facilitate coverage of each household with bank accounts. The Department 
of Telecom is working on priority basis to expand telecom connectivity to rural areas for effective utilisation of digital financial inclusion.

\subsection{Implementation}

Expansion of the outreach through enhanced geographical coverage of the rural financial network through Sub Service Area covering all the 6 lakh villages with panchayats as the nodal point.

Opening of Basic Savings Bank Deposit Accounts ( BSBDA )for all adult citizens with simplified KYC norms with one address identity and address proof including opening of small accounts with limitations of credit upto Rs 1 lakh a year, withdrawals upto Rs 10000/-a month and account balance upto Rs 50000/- at any point of time has been permitted

Each SB account holder would be given ATM/Debit (Ru Pay) card to increase cashless transactions and build credit history for greater entitlement for credit facility from formal financial system. It is also propose to provide all KCC holder with RuPay KCC card and non-agriculturist with RuPay debit card with inbuilt accident insurance of 1 lakh. This account would be seeded with the Aadhaar number of the account holder and would become the access point for Direct Benefit Transfers (DBT) from the Central Government / State Government / Local Bodies

Financial literacy sessions would be imparted on wide scale by bank branches regarding the skills to manage own money and credit facilities. Convergence with the efforts of the National Rural Livelihood Mission(NRLM) would be sought in order to open bank accounts for the Self Help Group (SHG) members. Overdraft (OD) up to `5,000/- would be provided to the customers only after complying six months of satisfactory saving/credit history .

Credit Guarantee Fund has been proposed to be created with a corpus of Rs $1000 \mathrm{cr}$.to provide guarantee cover to customers availing OD facility under PMJDY. The Rate of Interest on these accounts is proposed @ base rate $+2 \%$ or $12 \%$ whichever is lower All Government benefits under Direct Benefit Transfer are proposed to flow into this account facilitating servicing of interest \& minimise the chances of dormancy of the account..

Micro Insurance products will also be offered with existing scheme like Aam Admi Bima Yojana (Estimated target of $12 \mathrm{cr}$ families). Aadhaar Enabled Micro Insurance can be printed from CSC location below Rs 50000/-covering both life or non-life or both to be undertaken by intermediaries like NGOs, MFIs and SHGs.

The pension scheme named SWABALAMBAN launched by the Government of India in October 2010 for age income protection need of the unorganised//informal sector workers will also be synchronised with the scheme in due course.

\subsection{Role of technology}

The barriers to inclusion so far was the higher transaction costs for rural population which has been overcome with the ICT technology which has brought down the cost to affordable level and also capable of penetrating the farthest corner and people in the last mile with leveraging new technology like e-KYC, IMPS, AEPS, mobile banking etc. Technology has emerged as the key enabler in terms of affordable cost, precision and speed of outreach. The various stakeholders like banks, telecom operators and government departments need to converge with their models and action plans .The technological giants like IDBRT, NPCI and RBI are working incessantly to converge with CBS, ECS, RTGS, NEFT, Cheque Truncation and E-KYC, Immediate Payment systems, Mobile banking under USSD (presently $886 \mathrm{mn}$ mobiles in india), Micro ATMs biometric authentication enabled hand-held device which will support Deposit, Withdrawal, Fund transfer and Balance enquiry as most promising mode of serving the unbanked population.,

National Unified USSD platform, RuPay debit cards with flexibility of the product platform, high levels of acceptance and the strength of the RuPay brand-all of which will contribute to an increased product experience and Aadhar Enabled Payment System(AEPS) to reap the benefits of Direct Benefit Transfer.(DBT) are some of the highlights of the digital financial inclusion envisaged under PMJDY which has given it a distinct edge.

\subsection{Progress made so far}

The scheme got a flying start with 1.5 crore account opening day on the launching day Aug 28, 2014 which has gone upto nearly $12.40 \mathrm{cr}$ as on January 29, 2015 with a deposit base of nearly Rs $8000 \mathrm{cr}$. The main attraction has been the free accidental insurance cover of Rs 1 lakh which is bundled with the RuPay debit card. The move has been made more lucrative for the unbanked families with life cover of Rs $30000 /$ - for life time to the Head of the family subjected to review every 5 years. The premium for the accidental cover is to be borne by NPCl and cover by HDFC Ergo. Regarding the footing of the premium bill for life cover has not yet been finalised, but the life cover will be provided by LIC. About 78000 
camps were organised across the country on Aug 28 to enable the enrolments.

\subsection{Challenges in implementing PMJDY}

The unique philosophy of the programme PMJDY is a big move to bring the excluded vulnerable people to the fold of formal financial system, but some of challenges may affect its viability if not monitored and managed effectively as detailed below:.

\subsubsection{The issue of Multiple of accounts}

The scheme is essentially for the unbanked, but it is not amply clear those who are poor and having a bank account are eligible to open account and avail the benefits of the scheme. The mandating of a single identity proof to open an account encourages hope of higher insurance cover and overdraft in multiple accounts for which no robust mechanism has not been put in place.

\subsubsection{Infrastructural issues:}

The big volume of 75 million new Rupay debit cards to be issued under Jan Dhan Yojana and existing volume of 120million Rupay Kisan Cards when combined are likely to pose a problem. The infrastructural bottlenecks like poor broadband connectivity and poor power supply to ATMs, downtime of ATMs etc may also pose a big challenge. There is possibility of long queues at ATMs and higher risk of misuse and frauds due to lack of knowledge about ATM use is a possibility

\subsubsection{Efficiency of alternate channels}

Unless alternative channels work efficiently the handling of 103 basic savings accounts which have already opened during the initial phase of FI plan and proposed 75 million to be opened under the programme within January 26, 2015 may pose a big problem

\subsubsection{Financial literacy}

Awareness efforts are the major stigma that deters the optimum use of alternate channels and stimulate demands for usage financial services. Without financial literacy, the initiative would be half -backed.

\subsubsection{Inactive accounts}

The government is keen that each unbanked family has at least two accounts (including one for a woman member of the family).To handle the load of no frill basic bank accounts both existing and new the programme must ensure that regular flow of funds through Direct Benefit Transfer from government to people holds the key to success.

\subsubsection{Utilisation of overdraft}

The absence of any concrete mechanism of utilisation of the proposed overdraft of Rs 5000/- per household in 7.5 crore accounts may lead to potential bad debts of huge amount which is looming large on the horizon. Many unbanked people are not aware whether the amount is to be repaid back to Bank or simply the same is grant for which literacy initiative may help assuage the fear.

\subsubsection{Confusion regarding validity of insurance claims}

The life insurance is an inbuilt feature of the Rupay Debit Card and the insurance claim is acceptable only if the Rupay Card is considered active when the card is swiped within the stipulated time limit of 45 days before making the claim. Thus in order to keep the account and card active under PMJDY, it is essential that the status of the card should be maintained as active by using it at-least once a month. 


\subsubsection{Availability of ATMs in rural areas}

The huge number of debit cards proposed to be issued would be used to the benefit of excluded people if the requisite number of ATMs are available in rural areas.

\subsubsection{Other issues}

The major players like cooperative societies, banking or respondents, mobile service providers, postal service and new payment banks may be roped in and role synchronised for yielding the desired result.HR challenges required to man the proposed branch expansion needs to be overcome and proper coordination between RBI and government is the need of the hour for effective implementation. There should be close link between Bank officials and BC outlets The Rupay cards are to be swiped at least once in every 45 days to maintain the active status of the card which needs to be disseminated to common public in wide scale.

\subsubsection{Problems in ICT transactions}

The manifold increase in ICT transactions in the proposed scheme are linked to other infrastructural needs such as the broadband connections and electricity supply in remote villages. The handheld devices may also face problems to identify the biometrics of labourers and the old for Aadhar-enables Direct Benefit transfers

\section{Way Forward}

9.1Financial inclusion as implemented till date through RBI and govt initiatives and other stake holders like PSBs, RRBs, Cooperatives and MFIs have proved to be inadequate The need of the hour is to enlarge the few baby steps taken so far to great leap forward in order to meet the unmet demand. This requires a mission mode to connect all the unbanked households with universal access to formal banking system. PMJDY has taken a holistic view of the bottlenecks of earlier programme and repackaged with all the desired features to make more relevant and meaningful for the poor and vulnerable.

The mammoth task requires political will, bureaucratic support and constant intervention by RBI. If implemented well, PMJDY will monetize the economy, expand the outreach and lower subsidy bills. It is expected to unleash the hugely untapped potential of the people at the bottom of social pyramid .Financial inclusion can take off in a mission mode only if the strategies are skillfully integrated ranging from relaxation of regulatory norms, launching of new products and services to meet the requirement of low income people and institutionalization of the process to make it sustainable and scalable If the unbanked population which constitute half of our country's population are financially included and allowed to move from the subsistence marginal level to the main stream as producers and consumers of goods and services the huge magnitude of untapped potential of products /services which would be unleashed would have a multipliers effect on mainstream economy and of the poor in particular and may usher in prosperity and growth with regular flow of DBT funds of MNREGA wage payments and subsidy bills expected to be around Rs 400000 crore.

The innovations in technology and alternate delivery models, products and services catering to needs of rural unbanked clientele which is affordable and no frills holds the key to the success of the PMJDY. The new approach should focus on reinventing the existing strategies and reorienting the following endeavours for eliminating the social evil of exclusion.

For revitalising the Business Correspondent model the major concern is the remuneration paid to the Business correspondents which needs to be revisited and further streamlining the same with customised products and services catering to the needs of the low income households with greater flexibility and sorting out the teething issues which are constraining factors for its sustainability.

9.5 The framework/guidelines for licensing of small banks and payments banks are on the anvil which are expected to serve the credit and fund remittance needs of low income households, tenant farmers and oral lessees and other unorganised sector who are economically active to augment the cause of financial inclusion.

Financial education being a key tool for enlarging the banking habits of people through knowledge and awareness on basic banking services and management skills, the new initiative may impact the financial behaviour of excluded people to free themselves from low income, no assets and indebtedness, and better utilisation of overdraft facility in built in PMJDY and graduate to higher eligibility for credit facility from Formal Financial system.

Broadening the quality of services through up gradation of technological innovations through digitalisation of 
Financial Inclusion programme for increasing the outreach in the remotest corner. Various options through mobile banking,, handheld devices as remote banking terminals, people e- branch and information exchange and strengthening communication network will act as proverbial slip between the cup and the lip for last mile connectivity.

The various govt initiatives on e-governance need to be dovetailed with technologies being used in financial inclusion and all the stake holders like govt, civil society, banks, RBI etc should join hands together and converge with an objective to make inclusive agenda of growth a reality, The vision to wipe out financial untouchability would come true if the employment opportunities are created in rural and urban job seekers to job creators by setting up micro-enterprise in rural and urban India by involving the multi-skilled youths own the responsibility of transforming local economy to vibrant hubs of income generation and employment India needs a quick response from all corners to make PMJDY's tryst with new destiny a reality in the times to come.

\section{References}

Chakrabarty,K.C(2011):Financial Inclusion and Banks: Issues and perspectives, RBI bulletin, November issue, RBI

Dev,M.S(2006):Financial Inclusion: Issue and Challenges, Economic and Political weekly, Vo 41,pp43.10 to 43.13

Department of Financial Services (2014):"Sampoorn Vittiyea Samaveshan, An Approach Paper for Comprehensive Financial Inclusion",16 June.

Gandhi, M.M:Financial Inclusion in India-Issues and Challenges, Commerce Vol 1,Issue 3, June 2013,ISSN2320-7620

IDFC Rural Development Network (2013): India Rural Development Report 2012-13 (Delhi: Orient Blackswan).

Indira Rajaraman (2014): "More Complete Financial Inclusion", Business Standard, 24 March. Planning Commission (2012): Draft Twelfth Five-Year Plan 2012-17, Government of India.

Joshi, Deepali Pant: Strategy adopted for Financial Inclusion, Speech Delivered at Workshop on 24 January, 2014 at New Delhi organized by Govt Of Madhya Pradesh

Khan H.R.:Financial Inclusion and Financial stability: are they two sides of the same coin? Speech Delivered at BANCON 2011, at Chennai 4 November, 2011

Leladhar V: :Taking Banking Services to Common Man-Financial inclusion:RBI, Bulletin, Jan 2006 issue.

Mundra,S.S. on "Banking Renaissance:Inclusion, Innovation \& Implementation" Address by Deputy Governor, Reserve Bank of India the seventh Annual Banking Conference "Bank on it , 2014" organized bythe Narsee Monjee Institute of Management Studies in Mumbai on October 11, 2014

Puhazendi Venugopalan: Financial Inclusion -Forward Step for Microfinance Sector Vol 83, ,P 30,Indian Institute of Banking \& Finance June 2012

RBI (2013): "Committee on Comprehensive Financial Services for Small Businesses and Low Income Households - A Report" (Chair: Nachiket Mor), December.,2013

Ram Mohan, T T (2014): "Mor on Financial Inclusion: A Few Baby Steps, Not a Great Leap Forward",

Sriram, M S (2014): "Why the Nachiket Mor Committee Report on Financial Inclusion Disappoints", Live Mint, 10 January.

Shikha Sharma and S S Mundra (2014): Views on Report from Committee on Comprehensive Financial Services for Small Businesses and Low-income Households, Reserve Bank of India, 6 January.

Syed, Amir Hamza (2014): “New Beginning for Financial Inclusion”, 14 August, www.LIVEMINT.com

Thapar, Ashima: A study on the effectiveness of the Financial Inclusion Programme in India, VSRD International Journal of Business Management and research,Vol3, No 6 June 2013.

Thorat Usha, Deputy Governor,Reserve Bank of india, Speech delivered on Vision -2020-Indian Financial Services Sector hosted by NDTV in September 2008.

Teki S and Mishra R.S: Role of Microfinance on Financial Inclusion p87 published in by Acedemic Foundation,NewDelhi, 2012

Viswanathan, R (2014): "RBI Report on Financial Inclusion: A Review", Economic \& Political Weekly, Issue No 9, 1 March. 